\title{
The Understanding of Implicit Linguistic Knowledge in Second Language Research
}

\author{
Sami Sulaiman Alsalmi \\ Bristol University, Bristol, UK
}

\begin{abstract}
Implicit knowledge acquisition is the goal of second language (L2) learning. Ellis (2006; 2009) argues that it is implicit rather than explicit knowledge which underlines linguistic competence reflected in actual speech production and comprehension. Thus, this review aims to elucidatethe theoretical nature of implicit and explicit linguistics knowledge and how these types of knowledge are distinguished in terms of their representation and processing in use. The overall goal is to make the understanding of implicit knowledge easier to a wide audience of L2 researchers, especially those who are not interested in the absence of awareness of the target feature to be learnt at the point of learning.
\end{abstract}

Keywords: implicit knowledge, explicit knowledge and automaticity

\section{Constructs of L2 Implicit Knowledge}

Prior to elucidating the nature of implicit linguistics knowledge and how it is distinct from explicit knowledge, it is important to clarify what "linguistic competence" implies. Two competing theories delineate the concept of linguistic competence (Ellis, 2009). The first, following Chomsky's view (1965; 1986), claims that human beings are biologically endowed with an innate device mechanism (i.e., innate Universal Grammar) which functions as a guiding force of language acquisition. The assumption underlying Universal Grammar indicates that language is comprised of a set of abstract principles that describe central grammars of all natural languages. That is, language develops as a result of obtaining input from the environment with the support of an innate faculty. The second, drawing on connectionist theories of language learning, views linguistic competence as an elaborate, interlinked network of nodes that a human being constructs from input over time. That is, language learning, based on the connectionist view, arises neither from a deductive or inductive analysis of linguistic input, nor from the use of an innate language mechanism, but instead, it takes place based on the extraction of regularities from the input (Ellis, 2003). Although it is the ability of brain to make connections between units, exposure to these regularities frequently plays a crucial role in strengthening connections between nodes and unites. Complexes of networks are developed as a result of new relations is grown and new links are made between larger and larger units (see Gass \& Selinker, 2008 for a comprehensive review). Ellis (2005) claimed that, although the two theories appear oppositional, they share the notion that linguistic competence primarily encompasses the implicit knowledge. Accordingly, the two theories constantly deliberate over investigating mechanisms of learning leading to the promotion of implicit linguistic knowledge because the development of such knowledge is the goal of their theory.

Sami Sulaiman Alsalmi, a Ph.D. candidate in psycholinguistics, School of Education, University of Bristol, Bristol, UK. 
Admittedly, there is some ambiguity in the definition of the nature of implicit and explicit knowledge (Hulstijn, 2007; Robinson et al., 2013). Nevertheless, most L2 acquisition researchers have been unanimous that implicit knowledge fundamentally lies in automaticity (Ellis \& Roever, 2018; Cleeremans \& Jimenez, 2002; Ellis, 2015; Robinson et al., 2013). While there is no well-defined construct that obviously distinguishes automatic from non-automatic processing (or controlled processing), L2 acquisition-based research has viewed speed of language processing, with little or no conscious effort, as a prevailing diagnostic tool since this is most closely associated with fluency, and utterance fluency itself reflects acquisition, rather than learning (Segalowitz, 2003; Williams, 2009).

The interface between fast processing and attention is highly dominant in automaticity. As the efficiency of cognitive processing increases, the level of attention and effort involved to perform reduces. In other words, the processing speed and the ability to perform more processes increase. Competition for cognitive resources can be reflected in L2 learners' processing of the auditory input stream, specifically in the early stages of acquisition, in that form and meaning compete for learners' limited attention resources during input processing (see Van Patten, 1990; Wong, 2001 for a review). At this stage, a great deal of cognitive effort is invested to make connections effectively, drawing a tremendous amount of conscious attention to each action and stimulus. That is, any minor distractions (such as variation in prosodic signals) may easily cause a disruption to the processing of form and meaning simultaneously. However, following practice, processing of form-meaning connection in the auditory modality improves and becomes automatic, and requires significantly less effort and attention. That is, concurrent processes are executed that previously would have been a challenge.

In light of the above, automatic processing can be employed as a core indicative of implicitness. Ellis (2009, p. 12) affirmed that, "the procedures that comprise implicit knowledge can be easily and rapidly accessed in unplanned language use. In contrast, explicit knowledge exists as a declarative fact that can only be accessed through the application of attentional processes”. This indicates that implicit knowledge is available spontaneously and automatically and is employed in extemporaneous language use, presumably indicating that the brain has already internalized linguistic knowledge. Explicit knowledge, however, is accessible through controlled processing and intentional action, such as monitoring utterances.

From a cognitive psychology perspective, lack of awareness is the most prevalent basis of implicitness (Williams, 2009). It postulates that implicit knowledge also entails unconscious awareness where a language user is unconsciously aware of the underlying regularities governing linguistic structure. This is in contrast to explicit knowledge, which requires conscious knowledge of those regularities (Ellis, 2009). The following example illustrates the two types:

The new laptop that I bought it yesterday stopped working.

A language user with implicit knowledge is intuitively aware that the sentence above is ungrammatical and could find its deviating element, but may be unaware of the rule underlying the deviance. However, a user with explicit knowledge can verbalize that rule: The object of the verb is moved to sentence-initial position and the original position after the verb must be omitted (i.e., a relative clause).

However, more importantly, language users could have both implicit and explicit knowledge of the same linguistic structure. That is, they may be able to use the structure correctly and fluently in their oral production (e.g., counterfactual conditionals: if you had not passed the driving test, you would not have had a driving licence), and simultaneously possess conscious knowledge of the syntax guiding the structure: The past perfect 
tense is used following "if" in the dependent clause, and "would + have" followed by a verb in the past participle is used in the main clause.

This combined knowledge results from two sources: either the language users, whose first language was acquired implicitly, have been exposed to the metalinguistic explanation (i.e., explicit learning) of their implicit language knowledge (i.e., native language) or implicit knowledge might have been derived from explicit knowledge when L2 learners are exposed to meaningful, copious practice. The latter is manifested in the continuous attempts of L2 studies (e.g., Akakura, 2012; Erlam et al., 2009; Reinders \& Ellis, 2009; Toth \& Guijarro-Fuentes, 2013) seeking to elucidate which learning conditions foster the automatic process of grammatical rules, which is taken as a principled behavioral indication of implicit knowledge.

\section{Implicit and Explicit Learning}

\section{Implicit Learning}

Explicit and implicit learning are typically viewed as two oppositional conditions and both have been a long-term focus in L2 literature review. Theoretically, the distinction between implicit and explicit learning can be basically determined by awareness of what is being learned and the intentionality of learning (Ellis, 2009; Williams, 2009).

Ellis (1994) defined implicit learning as the "acquisition of knowledge about the underlying structure of a complex stimulus environment by a process which takes place naturally, simply and without conscious operations” (p. 1). Accordingly, implicit learning can be referred to as a manipulated learning condition in which participants learn grammatical structure in the absence of intentionality and awareness of the structure to be learnt at the point of learning (Williams, 2009). A realistic example of implicit learning is a child's first language acquisition. Especially prior to starting formal schooling (at approximately age six), children acquire complex linguistic knowledge spontaneously, unintentionally, and implicitly without the ability to describe that linguistic knowledge (see Hulstijn, 2015, for review). Thus, growingly greater strides in language acquisition are noticeable in children, which eventually outstrip the adults. An adult's learning of a second language, conversely, typically involves some degree of formal instruction and error correction (Ioup, 1995).

In light of the L2 adult learning discussed above, learning without planning or intending to can be methodologically feasible. For instance, participants might learn grammatical structure in the course of a meaning-focused activity. However, there is debate as to whether any learning is likely to occur without some degree of awareness. This raises a crucial inquiry regarding the exact meaning of "awareness". Schmidt (1990; 1995; 2001), who suggested the "Noticing Hypothesis", distinguished between two types of awareness: awareness as noticing (involving perception) and metalinguistic awareness (involving understanding). The former involves conscious attention to "surface elements", while the latter requires awareness of the underlying abstract rule that governs particular linguistics. Schmidt (2001) argued that as manipulation of noticing (i.e., the target structure in the input is emphasized in some way: through glossing, underlining, intonation, and so on) involves at least some degree of awareness, there is no such thing as a complete implicit learning condition. Thus, a better definition of implicit language learning, as Schmidt (2001) suggested, is learning without any metalinguistic awareness.

The conceptual and methodological complexity on implicit learning has led distinguishing implicit from incidental learning in the field of L2 learning research. As implicit learning refers to learning that proceeds without awareness of what is being learned and without the intention to learn it, the incidental case refers to 
knowledge that "is acquired in the absence of instructions or intention to learn, but the subject retains conscious access to that knowledge” (Pervin \& John, 1999, p. 587). That is, both types of learning (implicit and incidental) are unintended (or unplanned), but the difference lies in consciousness; that is, implicit learning is unconscious (i.e., unaware of acquired knowledge "i.e., resulting in an abstract representation of language") while incidental learning is conscious (i.e., aware of knowledge being learnt).

\section{Explicit Learning}

While implicit learning involves the absence of intentionality and awareness of the structure to be learnt at the point of learning, explicit learning requires an intention to learn and the use of conscious knowledge at the point of learning. That is, participants are aware that they are supposed to learn something, and they are usually informed that there will be a test on what they have learned. As implicit learning retains unaware of learning, it is assumed to proceed with a minimum of attentional resources. However, in explicit learning, the metalinguistic knowledge is verbalized in the pattern of rules and, hence, more processing demands are placed on working memory capacity (Wang, 2017).

As mechanisms involved in first language acquisition, which occurs implicitly, are not sufficient for L2 acquisition due largely to learnt attention and L1 transfer, the success of L2 acquisition needs to conquer the processing habits of the first language by means of deploying supplementary resources of explicit/intentional learning. N. Ellis (2005; 2011) claims that adult language acquisition usually involves explicit learning where Language acquisition can be speeded by explicit instruction. He adds that "learned attention limits the potential of implicit learning, and that is why explicit learning is necessary in L2 acquisition” (Ellis, 2015, p. 13). In the same vein, R. Ellis (2002, p. 145) asserts that the last 20 years of empirical investigations into the effectiveness of L2 instruction demonstrate that focused L2 instruction results in large target-oriented gains, that explicit types of instruction are more effective than implicit types, and that the effectiveness of L2 instruction is durable".

The explicit learning process can be indicated as either inductive or deductive. According to Decoo (1996), deductive learning is a "process that goes from the general to the specific, from consciously formulated rules to the application in language use” (p. 96). To put it differently, metalinguistic knowledge (i.e., an explanation) of a grammatical rule is provided first, followed by examples and practice. Inductive learning, by contrast, refers to a process that goes from the specific to the general (i.e., forming generalizations) on the basis of authentic language containing examples of the rule where learners then are asked to discover the rule from those prototypical examples. In this regard, both types of deductive and inductive learning are considered explicit "because there is either explicit rule explanation or guided instruction for students to attend consciously to particular forms” (Wang, 2017, p. 45).

\section{The Interface Issue}

The distinction between implicit and explicit knowledge is arguably less complicated than the implicit/explicit learning distinction (Ellis, 2015). However, these distinctions raise three crucial questions: Can adult L2 learners acquire a foreign language in a complete implicit context as children do in learning their first language? Can explicit knowledge convert into or facilitate the acquisition of implicit knowledge? Does explicit instruction result in the acquisition of implicit as well as explicit knowledge? (Ellis, 2009) These questions relevant to L2 acquisition are reminiscent of proposals and debates sparked by Krashen (1981; 1985), which can reflect three distinct answers. The first was referred to the notion that implicit and explicit 
knowledge are dissociated and distinct; they are located and accessed by different areas of the brain. Accordingly, implicit language knowledge is acquired only via exposure and cannot be explicitly taught. Explicit language knowledge also remains explicit and cannot become implicit even after much practice (Paradis, 1994; Robinson et al., 2013). This belief is called the non-interface position.

The strong interface position, first advanced by Sharwood-Smith (1981) and boosted by DeKeyser (2003), claims that explicit knowledge can represent a base for practice. The resulting proceduralization eventually automatizes explicit knowledge. This automatized knowledge is reflected in rapid online processing and becomes available through automaticity and consistency of L2 learners' speech. Like implicit knowledge, automatized knowledge is accessed without or with very limited attentional actions to linguistic form. However, DeKeyser (2003) argued that this automatized knowledge learned explicitly should be distinct from knowledge learnt implicitly. In this sense, three types of knowledge can be built: explicit knowledge, automatized explicit knowledge, and implicit knowledge. DeKeyser (2003) suggests that automatized knowledge can be considered to be "functionally equivalent" to implicit knowledge.

Finally, the weak interface position suggests that explicit knowledge can become implicit knowledge in an indirect manner. It postulates that this conversion develops only under specific constraints. The first version, proposed by Ellis (1993), posited that the transfer of explicit to implicit knowledge takes place if the learner is developmentally ready to acquire the linguistic structure. The second version, theorized by Ellis (1994), suggested that explicit knowledge can facilitate the development of implicit knowledge by "alerting learners to what they need to attend to when processing input” (Robinson et al., 2013, p. 252). MacWhinney (1997) supports this theory, finding that learning with some clues and hints produces better gains than learning without them. The third version of this position refers to the notion that learners can use explicit knowledge to generate output and this output can work as "auto-input" to the implicit system (Schmidt \& Frota, 1986; Sharwood-Smith, 1981).

The three distinct positions reviewed above have their advocates and have been broadly controversial topic in L2 acquisition research. However, Ellis (2009) argued the issue of interface between these positions has not been subjected to an experimental scrutiny, and he referred the reason to the absence of consensus in terms of robust instruments for examining whether learning effect occurred as a result of instruction or exposure composed of one type of knowledge (implicit or explicit), or some combination of the two. Wang (2017), on the other hand, claimed that most recent studies lend to support the indirect, weak interface position; however, more examination and evidence is required for supporting this claim.

Even though the topic of the interface has been substantially disputed and no clear conclusions are drawn from the discussions, Ellis (2015) strongly argued that, this should not necessarily be the case because implicit/explicit knowledge and implicit/explicit learning are associated. More specifically, implicit learning could result in explicit knowledge as a learner may become spontaneously aware of linguistic rules in the input (Williams, 2009), or when a learner consciously processes a chunk that was acquired implicitly and then builds up an explicit generalization about its linguistic form. This is specifically manifested in adult language learners in contexts where the learnt language is considered as an object rather than as a communicative tool (Ellis, 2015). Explicit learning may also result in implicit knowledge. This can occur when a pupil explicitly learns a rule and then is exposed to copious and repeated practice; explicit knowledge becomes automatized and may come to affect behaviour without awareness. Ellis (2011) posited that the human mind is "collaborative" in the sense that explicit knowledge continuously interfaces with the processes required in implicit learning. The 
following figure reveals the hypothesized relationships between implicit and explicit learning and implicit and explicit knowledge.

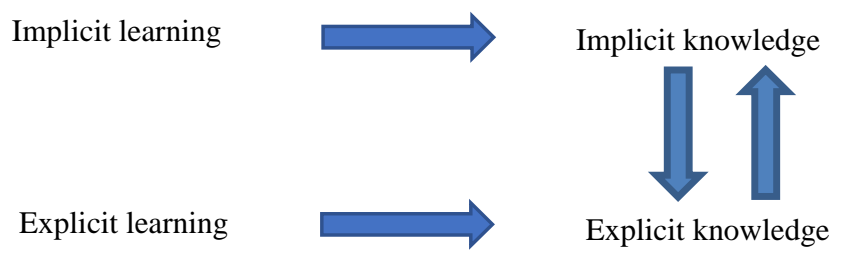

Figure 1. The relationships between implicit/explicit learning and implicit/explicit knowledge (Adopted from Ellis, 2015).

As shown in Figure 1, the instruction that is employed for either type of learning might lead to either type of knowledge. This provides a clear indication that the learning experience is the impetus for establishing the type of knowledge acquired (Ellis, 2015).

\section{Measures of L2 Implicit Knowledge}

The growing empirical need for the development of competency measures to assess implicit knowledge has absorbed the interest of researchers in the areas of SLA, language assessment and psycholinguistics. A number of research studies arising from factor analysis and correlational studies have attempted to establish measures hypothesized to tap into two different types of knowledge: implicit and explicit knowledge (e.g., Bowles, 2011; R.Ellis, 2005; Erlam, 2006; Kim \& Nam, 2017; Loewen, 2009). These studies have obtained consistent evidence to indicate that an elicited imitation task (EIT) and timed grammaticality judgement task (timed GJT) are better measures of L2 implicit knowledge, whereas untimed grammaticality judgment tasks and metalinguistic knowledge tests are better measures of L2 explicit knowledge. The way in which the measures of implicit knowledge are designed and manipulated distinguishes them from those tapping into explicit knowledge. The most dominant factor associated with the automaticity inherent in implicit knowledge is speed of processing. Thus, the two tasks (i.e., EIT and timed GJT) involve time constraints to diminish the likelihood of accessing explicit knowledge (i.e., the ability to monitor or ponder over the appropriate syntax is suppressed). The EIT, in particular, involves an extra factor, which is that test takers are required to focus attention on meaning rather than form so that rote verbatim is restrained. To put it simply, the EIT requires test takers to reproduce utterances that he or she has heard while processing them for semantic meaning and correcting any syntactic anomalies, under time pressure. The spontaneous and fluent correction of syntactic anomalies is assumed to be a strong and sufficient indication that automatic language processing is in operation (i.e., implicit knowledge has been accessed, if available, Erlam, 2006). The GJT, in contrast, requires a test taker to judge, from the first impression, whether a visually or aurally presented sentence is grammatically acceptable or not under time constraints. Rapid linguistic behavioral response to the timed GJT sentences is hypothesized to reflect a high degree of automaticity of the acquired knowledge (Loewen, 2009).

\section{Conclusion}

To conclude the theoretical work above, the dominant concept which guides the understanding of implicit knowledge in the L2 research is whether grammatical knowledge is available for use in automatic processing reflected in fast processing. This can be supported by Ellis and Roever's (2018, p. 2) claim that "automatic processing is a defining characteristic of implicit knowledge and, therefore, that any language behavior 
involving automatic processing affords evidence of the learner's implicit knowledge”. This is the case irrespective of the distinct theoretical views regarding whether explicit knowledge is proceduralized to become automatized knowledge, "functionally equivalent" to implicit knowledge, or simply implicit knowledge acquired implicitly. The interface between these views should necessarily not be the case; as the most important, practical understanding is how implicit and explicit linguistic knowledge are distinguished in terms of their processing in use.

Two assessment tasks are presumed to measure implicit knowledge: the elicited imitation task and timed grammaticality judgement task, both of which are commonly employed to observe L2 learners' implicit knowledge development in L2 research. Responses to both timed GJT and EIT reflect underlying automatic processing in a similar way (Kim \& Nam, 2017), where the most shared factor associated with the automaticity is speed of processing. The former requires only visual processing (or only auditory processing if it is presented in an auditory mode) while the latter requires auditory input processing and oral output possessing. Thus, the EIT is likely to impose greater processing demands on L2 learners' cognitive resources than the processing of visual text (i.e., GJT), resulting in poorer performance in the EIT.

\section{References}

Akakura, M. (2012). Evaluating the effectiveness of explicit instruction on implicit and explicit L2 knowledge. Language Teaching Research, 16(1), 9-37.

Bowles, M. A. (2011). Measuring implicit and explicit linguistic knowledge. Studies in Second Language Acquisition, 33(02), 247-271.

Chomsky, N. (1965). Aspects of the theory of syntax. Cambridge, Mass.: MIT Press.

Chomsky, N. (1980). Rules and representations. Oxford: Blackwell

Cleeremans, A., \& Jimenez, L. (2002). Implicit learning and consciousness: A graded, dynamic perspective. In R. M. French \& A. Cleeremans (Eds.), Implicit learning and consciousness: An empirical (pp. 1-46). East Sussex: Psychology Press.

Decoo, W. (1996). The induction-deduction opposition: Ambiguities and complexities of the didactic reality. IRAL: International Review of Applied Linguistics in Language Teaching, 34(2), 95-118.

DeKeyser, R. (2003). Implicit and explicit learning. In C. Doughty \& M. Long (Eds.), Handbook of second language acquisition (pp. 313-348). Malden: Blackwell.

Ellis, N. (2003). Constructions, chunking and connectionism: The emergence of second language structure”. In C. J. Doughty \& M. H. Long (Eds.), The handbook of second language acquisition (pp. 63-103). Malden, MA: Blackwell.

Ellis, N. C. (2005). At the interface: dynamic interactions of explicit and implicit language knowledge. Studiesin Second Language Acquisition, 27, 305-352.

Ellis, N. C. (2011). Implicit and explicit SLA and their interface. In C. Sanz and R. Leow (Eds.), Implicit andexplicit language learning: Conditions, processes and knowledge in SLA \& Bilingualism (pp. 35-47). Washington, DC: Georgetown University Press.

Ellis, N. C. (2015). Implicit and explicit language learning: Their dynamic interface and complexity. In P. Rebuschat (Ed.), Implicit and explicit learning of languages (pp. 3-23). Philadelphia, PA: John Benjamins.

Ellis, R. (2005). Measuring implicit and explicit knowledge of a second language: A psychometric study. Studies in Second Language Acquisition, 27(02), 141-172.

Ellis, R. (2009). Implicit and explicit learning, knowledge and Instruction. In R. Ellis, S. Loewen, C. Elder, R. Erlam, J. Philp, \& H. Reinders (Eds.), Implicit and explicit knowledge in second language learning, testing and teaching (pp. 1-25). Bristol: Multilingual Matters.

Ellis, R. (2015). Form-focused instruction and the measurement of implicit and explicit L2 knowledge. In P. Rebuschat (Ed.), Implicit and explicit learning of languages (pp. 417-441). Amasterdam: John Benjamins.

Ellis, R., \& Roever, C. (2018). The measurement of implicit and explicit knowledge. The Language Learning Journal, 1-16.

Erlam, R. (2006). Elicited imitation as a measure of L2 implicit knowledge: An Empirical validation study. Applied Linguistics, 27(3), 464-491. 
Erlam, R., Loewen, S., \& Philp, J. (2009). The roles of output-based and input-based instruction in the acquisition of L2 implicit and explicit knowledge. In R. Ellis, S. Loewen, C. Elder, R. Erlam, J. Philp, \& H. Reinders (Eds.), Implicit and explicit knowledge in second language learning, testing and teaching (pp. 241-261).

Gass, S. M. (2013). Second language acquisition: An introductory course. Routledge.

Hulstijn, J. (2007). Psycholinguistic perspectives on language and its acquisition. In J. Cummins and C. Davison (Eds.), International Handbook of English Language Teaching (pp. 783-795). New York: Springer.

Hulstijn, J. H. (2015). Explaining phenomena of first and second language acquisition with the constructs of implicit and explicit learning: The virtues and pitfalls of a two-system view. In P. Rebuschat (Ed.), Implicit and explicit learning of languages (pp. 25-47). Amsterdam, The Netherlands: John Benjamins.

Ioup. (1995). Evaluating the need for input enhancement in post-critical period language acquisition. In Singleton and Lengyel (pp. 95-123).

Kim, J., \& Nam, H. (2017). Measures of implicit knowledge revisited: Processing modes, time pressure, and modality. Studies in Second Language Acquisition, 39(3), 431-457.

Krashen, S. (1981). Second language acquisition and second language learning. Oxford: Pergamon Press.

Krashen, S. (1985). The input hypothesis: Issues and implications. London: Longman.

Loewen, S. (2009). Grammaticality judgment tests and the measurement of implicit and explicit L2 knowledge. In R. Ellis, S. Loewen, C. Elder, R. Erlam, J. Philp, \& H. Reinders (Eds.), Implicit and explicit knowledge in second language learning, testing and teaching (pp. 94-112). Bristol: Multilingual Matter.

Paradis, M. (1994). Neurolinguistic aspects of implicit and explicit memory: Implications for bilingualism and SLA. In N. C. Ellis (Ed.), Implicit and explicit learning of languages (Vol. 393, pp. 393-419). London: Academic Press.

Pervin, L. A., \& John, O. P. (1999). Handbook of personality: Theory and research. New York: Elsevier.

Reinders, H., \& Ellis, R. (2009). The effects of two types of input on intake and the acquisition of implicit and explicit knowledge. In R. Ellis, S. Loewen, C. Elder, R. Erlam, J. Philp, \& H. Reinders (Eds.), Implicit and explicit knowledge in second language learning, testing and teaching (pp. 281-302). Bristol: Multilingual Matters.

Robinson, P., Mackey, A., Gass, S. M., \& Schmidt, R. (2013). Attention and awareness in second language acquisition. In S. M. Gass and A. Mackey (Eds.), The Routledge handbook of second language acquisition (pp. 247-267). Abingdon: Routledge.

Schmidt, R. (1990). The role of consciousness in second language learning. Applied Linguistics, 11(2), 129-158.

Schmidt, R. (2001). Attention. In P. Robinson (Ed.), Cognition and second language instruction (pp. 3-30). Cambridge: Cambridge University Press.

Segalowitz, N. (2003). Automaticity and second languages. In M. H. Long and C. Doughty (Eds.), The handbook of second language acquisition (pp. 382-408). Oxford: Blackwell.

Sharwood-Smith, M. (1981). Consciousness-raising and the second language learner. Applied Linguistics, 2(2), 159-168.

Toth, P., \& Guijarro-Fuentes, P. (2013). The impact of instruction on second-language implicit knowledge: Evidence against encapsulation. Applied Psycholinguistics, 34(6), 1163-1193.

VanPatten, B. (1990). Attending to form and content in the input. Studies in Second Language Acquisition, 12(03), $287-301$.

Wang, Y. (2017). English transitivity alternation in second language acquisition: An attentional approach. Routledge.

Williams, J. N. (2009). Implicit learning in second language acquisition. In W. C. Ritchie and T. K. Bhatia (Eds.), The new handbook of second language acquisition (pp. 319-353). Bingley: Emerald.

Wong, W. (2001). Modality and attention to meaning and form in the input. Studies in Second Language Acquisition, 23(03), 345-368. 